Indexed by

\section{Scopus}

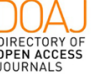

Crossref

KOBSON

81'Google

\title{
THEORETICAL RESEARCH OF THE EXTERNAL TEMPERATURE INFLUENCE ON THE TRACTION AND SPEED PROPERTIES AND THE FUEL ECONOMY OF CARGO-CARRYING VEHICLES
}

\section{Zhasur Kulmukhamedov \\ Tashkent Automobile and Road Technical School, Faculty of Automobile Transportation, Department of Automobile, Tashkent, Uzbekistan}

\section{Yulduz Kulmukhamedova}

Tashkent Automobile and Road Technical School, Faculty of Automobile Transportation, Department of Automobile, Tashkent, Uzbekistan

\author{
Ravshan Khikmatov \\ Tashkent State Transport \\ University, Faculty of \\ Engineering of Automobile \\ Transport, Department of \\ Vehicle Engineering, \\ Tashkent, Uzbekistan
}

\author{
Alisher Saidumarov \\ Scientific-Production Center \\ "Uzavtotranstekhnika", \\ Tashkent, Uzbekistan
}

Key words: fuel consumption, driving mode, cargo-carrying vehicle, external temperature

Cite article:

Zhasur, K., Ravshan, K., Alisher, S., \& Yulduz, K. [2021]. Training neural networks using reinforcement learning to reactive path planning. Journal of Applied Engineering Science, 19(1) 68 - 76. DOI:10.5937/jaes0-27851

Online aceess of full paper is available at: www.engineeringscience.rs/browse-issues 


\title{
THEORETICAL RESEARCH OF THE EXTERNAL TEMPERATURE INFLUENCE ON THE TRACTION AND SPEED PROPERTIES AND THE FUEL ECONOMY OF CARGO-CARRYING VEHICLES
}

\author{
Zhasur Kulmukhamedov'*, Ravshan Khikmatov'2, Alisher Saidumarov³, Yulduz Kulmukhamedova1 \\ ${ }^{1}$ Tashkent Automobile and Road Technical School, Faculty of Automobile Transportation, \\ Department of Automobile, Tashkent, Uzbekistan \\ ${ }^{2}$ Tashkent State Transport University, Faculty of Engineering of Automobile Transport, \\ Department of Vehicle Engineering, Tashkent, Uzbekistan \\ ${ }^{3}$ Scientific-Production Center "Uzavtotranstekhnika", Tashkent, Uzbekistan
}

The aim is to develop a methodology for determining analytically the fuel consumption in a hot climate and substantiate reliability, as well as the possibility of its application by comparison with test results. The article proposes analytical methods for calculating fuel economy and traction-speed properties when modeling the movement of cargo-carrying vehicles on real routes, based on theoretical and experimental studies in a hot and dry climate, which allows for determining the efficiency of cargo-carrying vehicles objectively in terms of traction and speed, fuel and economic indicators. Using the statistical processing of experimental, theoretical research data, the authors calculate the coefficient X2, which allows for evaluating the adequacy of the mathematical model and experimental data. The paper provides for an assessment of fuel economy and traction and speed properties. The authors presented the results in graphs for the ease of evaluating the effect of external temperature on fuel consumption and the average speed of a road train. The authors' methodology allows for determining the efficiency of cargo-carrying vehicles in a hot and dry climate.

Key words: fuel consumption, driving mode, cargo-carrying vehicle, external temperature

\section{INTRODUCTION}

The most important problems of our time are the development of ways of rational use of energy resources and their economy. Issues of fuel economy are of extremely high importance. Cargo-carrying vehicles and road trains are parts of the main consumers of liquid fuel and, therefore, increasing the fuel economy of this type of transport is a significant reserve of its economy [1, 2].

When developing measures to increase the constructive efficiency of cargo-carrying vehicles that contribute to improving fuel economy, it is necessary to have data on the value of each of the components of resistance to vehicle movement and on the influence of structural and operational factors on them in hot climates [3-5].

Using theoretical and experimental data banks on the operational properties of cargo-carrying vehicles, especially the interaction of wheels with the road, tire design, internal aerodynamic drag, etc., significantly complicates their use due to the complexity of the application of measurement methods, as well as processing of results. In addition, the absence of reliable analytical dependencies between the components of resistance to movement and fuel consumption influence the results; it is difficult to determine by calculation the effectiveness of the introduced structural changes, and the choice of optimal solutions in conditions of elevated external temperatures. In connection with the above, the development of rational methods for assessing fuel economy is relevant [3].

The development of analytical methods for calculating fuel economy in modeling the movement of cargo-carrying vehicles in hot climates is a relevant task. The solution to this task can significantly reduce the cost of material and financial resources at the design and rationing stage in operating conditions [6].

\section{MATERIALS AND METHODS}

Gusakov et al. [7] discuss a method for improving the fuel economy of a power plant of a motor vehicle with an electromechanical transmission. Calculation studies of the energy balance of the power plant of the car during its movement under the new European Driving Cycle (NEDC). Driving cycles, used for evaluation of the integral exhaust gas toxicity indicators of motor vehicle engines, helped in simulating the actual operating modes of a motor vehicle engine. Gusakov et al. [7] consider the main factors affecting fuel economy indicators. The authors developed a model and conducted virtual tests using the GT-SUITE software package.

According to Zezyulin et al. [4, 5] the analysis of the results demonstrated the possibility of using the calculation and experimental methodology for estimating the fuel consumption of a motor vehicle when driving along a given route at the design and development stage. This analysis can serve as the basis for developing an improved 
theoretical methodology for calculating fuel consumption in working conditions

Karnaukhova [8] and Karnaukhov and Karnaukhov [9] determine the issue of the influence of changes in density, pressure and air temperature on the operation of an internal combustion engine was considered and the effective specific fuel consumption when changing these parameters Karnaukhova [8] and Karnaukhov and Karnaukhov [9] found that at low air temperatures, the difference in barometric pressure has less effect on fuel consumption than at high. The low density of air at high temperatures explains this pattern. The effective specific fuel consumption at low temperatures and barometric pressure drops for diesel engines increases within 9\%, at high temperature - from $8 \%$ to $15 \%$. Therefore, heating the air in the intake manifolds of the engines to a temperature of more than $67^{\circ} \mathrm{C}$ at any time of the year increases fuel consumption. It is advisable to preheat the air at the engine inlet only at low external temperatures, since in other cases this leads to a decrease in its density, enrichment of the fuel-air mixture and an increase in fuel consumption.

Belov and Anisimov [10] consider the influence of low external temperatures on the change in operational indicators (fuel consumption, environmental indicators) of motor vehicles equipped with diesel engines, as well as the determination of the coefficient of adaptability to low temperatures in terms of fuel consumption. The decrease in fuel consumption with decreasing air temperature at the engine inlet occurs due to an increase in the coefficient of excess air, the speed and completeness of fuel combustion, which has a greater effect on its consumption than increasing the ignition delay period. Because of the calculations, the mathematical dependence of the influence of negative external temperatures on the vehicle's fitness coefficient for low-temperature operating conditions for fuel consumption has been determined.

The issue of reducing the operational fuel consumption of motor vehicles' power plants requires close attention since the restrictions on $\mathrm{CO}_{2}$ emissions are legislative in nature and will be toughened over time [7, 11]. Modern driving cycles, originally developed to assess the environmental performance of motor vehicles, do not fully reflect the specifics of the movement of modern transport vehicles in actual use. It is important to recognize that the use of experimental-calculation methods for estimating operational fuel consumption can significantly reduce the amount of expensive and lengthy experimental studies without reducing the accuracy of the results by reducing the calculations to a single methodological approach. There is a need for further research to improve the methods for an objective assessment of $\mathrm{CO}$ emissions by motor vehicles' power plants in order to find rational ways to reduce the operational fuel consumption of transport vehicles.

The fuel efficiency of cargo-carrying vehicles in various climatic conditions depends on a combination of proper- ties that determine fuel consumption. The multifactorial effect of the influence of a hot-dry climate, in particular, the external temperature, on the engine's performance, determine the complexity of evaluating the fuel economy of cargo-carrying vehicles by analytical methods when driving in real road conditions [3].

The cost of fuel for engines can be up to $40 \%$ of all costs for its operation among the components of the economic performance of a motor vehicle. When choosing a cargo-carrying vehicle, its fuel efficiency is crucial. Therefore, reducing fuel consumption during the development of new models or their modernization is the most important task. Its economic component can be reduced using calculation methods for estimating fuel consumption [12].

\section{The methodology for calculating the traction and speed properties and fuel consumption in modeling the movement of cargo-carrying vehicles at elevated temperatures}

The analytical model of the movement of a truck along the route uses the model by Kulmukhamedov [3]. However, the authors introduced the corresponding corrective dependencies into the structure of the differential Equation of motion, considering changes in the components of the differential Equation under the influence of external temperature.

The analytical dependencies describing the process of movement of road trains is the source material for mathematical support. The main one is the differential Equation of the movement of a cargo-carrying vehicle over a given section of roads:

$\frac{d v}{d t} m_{n p}=a_{i} v_{a}^{2}+b_{i} v_{a}+c$

where $\mathrm{m}_{\mathrm{rm}}=\mathrm{m}_{\mathrm{gvw}} \delta_{\text {ric }}$ is the motor vehicle reduced mass. $\delta_{e p}=1+\frac{J_{\partial} U_{T i}{ }^{2} \eta_{T}+\Sigma J_{K}}{m_{a} \cdot r_{\partial} r_{k}} \quad$ is the rotation inertia coeffi-

cient at the acceleration in ith gear;

$m_{g v w}$ is the gross weight of the vehicle;

$u_{v s}$ is the vehicle speed;

$r_{e r}$ is the wheel effective radius;

$r_{r r}$ is the rolling radius;

$J_{\partial}$ is the flywheel's mass moment of inertia;

$\Sigma J_{\text {timw }}$ is the total inertia moment of the wheel;

$U_{T i}$ is the total gear reduction;

$\eta_{T}$ is the gear's coefficient of efficiency.

Coefficients $a_{i}, b_{i}, c_{i}$ are determined by the Equation:

$a_{i}=a_{m}^{\mathrm{T}} \cdot \frac{U_{\mathrm{Ti}}^{3} \cdot \eta_{\mathrm{Ti}} \cdot K_{\mathrm{p}}}{r_{d} \cdot r_{k}^{2}}-K_{\mathrm{B}} \cdot F \cdot$

$$
\cdot\left[\left(1-\frac{\beta_{0}}{\beta_{a}}\right)+\frac{1}{K_{\mathrm{B}} \cdot \beta} \sum_{i=1}^{n}(-1)^{i+1} \cdot \frac{\alpha_{i}^{2} \cdot \rho_{i}}{2} \cdot \frac{T_{i+1}+T_{i}}{2 \cdot T_{i}}\right]
$$

$b_{i}=b_{m}^{\mathrm{T}} \cdot \frac{U_{\mathrm{Ti}}^{2} \cdot \eta_{\mathrm{Ti}} \cdot K_{\mathrm{p}}}{r_{d} \cdot r_{k}}$

$c_{i}=c_{m}^{\mathrm{T}} \cdot \frac{U_{\mathrm{Ti}} \cdot \eta_{\mathrm{Ti}} \cdot K_{\mathrm{p}}}{r_{d}}-f \cdot G_{a} \cdot \cos \alpha \pm \sin \alpha$ 
where $a_{m}{ }^{\top}, b_{m}{ }^{\top}, c_{m}{ }^{\top}$ are the coefficients of the Equation

$M_{e}^{T}=a_{m}^{T} \cdot \omega_{e}^{2}+b_{m}^{T} \cdot \omega_{e}+c_{m}^{T}$

of the dependence of torque on the angular velocity of the motor shaft. The coefficients are determined by the value of the external temperature and the rack travel position;

$K_{\text {cfep }}$ is the correction factor of engine power;

$K_{a d c}$ is the air drag coefficient;

$F$ is the frontage area of the motor vehicle;

$\beta_{0}$ and $\beta a$ are the coefficients of the relative clear area of the input and output sections;

$\rho_{i}$ is the atmospheric density;

$T_{i}$ is the external temperature.

$f$ is the coefficient of rolling resistance;

$G_{a}$ is the weight of the vehicle.

The $f$ coefficient is determined by the Equation:

$f=f_{0}+K_{f} \cdot \vartheta_{a}^{2}$

where $f_{0}$ is the coefficient of rolling resistance at low speed;

$K_{f}$ is the speed factor.

It follows that when simulating the movement of a road train on a PC, it is necessary to know the angular velocity of the engine crankshaft and the rack travel position to determine motion indicators. The angular velocity is calculated based on the speed of the train using the wellknown Equation:

$\omega_{e}=\frac{\vartheta_{a} \cdot U_{\mathrm{T} i}}{r_{\mathrm{K}}}$

External and partial engine characteristics are used to determine the rack travel position. First, the power to overcome the total resistance forces is calculated:

$N_{\Sigma}=N_{j a}+N_{\psi}+N_{\mathrm{B}}+N_{\mathrm{T}}$

where $N_{j a}$ is the power spent to overcome acceleration resistance;

$N_{\psi}$ is the power spent to overcome the resistance of the road;

$N_{a r}$ is the power spent to overcome air resistance;

$N_{t}$ is the power spent on overcoming transmission resistance.

Using the Equation $\mathrm{N}_{\mathrm{e}}=\mathrm{N}_{\Sigma} / \mathrm{\eta}_{\mathrm{T}}$, it is possible to find the required engine power. By comparing $\mathrm{Ne}$ with engine power values for different $h p$ for a given value of $\omega_{e}$ and $T_{\text {ext }}$, it is possible to find the power values of the closest $\mathrm{Ne}$ and the corresponding rack travel position. It should be noted that the given va corresponds to the initial moment of the calculation step, and the obtained value of $h p$ is used for the next calculation step.

Since partial speed characteristics are available only at values of $h_{p}$ multiple of 10, the values of the power $N_{e}$ are not always equal to $N_{\Sigma}, \eta_{T} N_{\Sigma}, \eta_{T}$, and this causes a certain error. Despite this, the proposed method has advantages over others, according to which engine power is found from the given values of the position of the fuel supply body and the angular velocity of the engine crankshaft. In this case, it is impossible to consider all the concomitant factors affecting the operating mode and fuel consumption of the car. According to the authors' methodology $Q_{o}, \omega_{e}, h_{p}$ are more real, since they are determined taking into account the influence of both design factors and the total resistance to movement on them, which allows for considering the change in engine power, efficiency transmission, coefficient of rolling resistance, drag coefficient, as well as external temperature.

The solution of the differential Equation 1 allows for determining the nature of the change in the movement of the road train on each section of the route. In this case, the initial speed on the road section and the segment length are taken as initial data.

In the model of a cargo-carrying vehicle's movement, the studied route is introduced as a set of segments of a certain length, each of which has constant profile parameters.

A road profile in the form of a sequence of linear sections of the corresponding length with a constant slope can be obtained either by processing the design documentation of the road, or experimentally using a special set of equipment.

When modeling the acceleration mode, the following Equations were used:

a) To determine the change in speed on the path segment equal to $\Delta S$ :

$\Delta \vartheta_{a}=\left(\left(a_{i} \cdot \vartheta_{a}^{2}+b_{i} \cdot \vartheta_{a}+c_{i}\right) /\left(m_{a} \cdot 9,8 \cdot \delta_{\text {вр }}\right)\right) \cdot \Delta S$

b) To determine the speed at the end of the segment:

$\vartheta_{a 2}=\vartheta_{a}+\Delta \vartheta_{a}$

c) To determine the time of movement on the segment:

- At $\Delta<0$ :

$\tau_{\mathrm{p}}=\left(\left(2 \cdot m_{a} \cdot 9,8 \cdot \delta_{\mathrm{Bp}} /\left(\sqrt{-\Delta} \cdot \operatorname{arctg}\left(\left(2 \cdot a_{i} \cdot \vartheta_{a}^{2}+b_{i}\right) /(\sqrt{-\Delta})\right)\right)-\right.\right.$ $-2 \cdot m_{a} \cdot 9,8 \cdot \delta_{\mathrm{вp}} / \sqrt{-\Delta} \cdot \operatorname{arctg}\left(\left(2 \cdot a_{i} \cdot \vartheta_{a}^{2}+b_{i}\right) /(\sqrt{-\Delta})\right)$

- At $\Delta>0$ :

$\tau_{\mathrm{p}}=m_{a} \cdot 9,81 \cdot \delta_{\text {вр }} / \sqrt{\Delta} \cdot \log \left|\left(2 \cdot a_{i} \cdot \vartheta_{a}-\sqrt{\Delta}\right) /\left(2 \cdot a_{i} \cdot \vartheta_{a 2}+b_{i}+\sqrt{\Delta}\right)\right| \cdot$ $\cdot\left(2 \cdot a_{i} \cdot \vartheta_{a}+b_{i}-\sqrt{\Delta}\right) /\left(2 \cdot a_{i} \cdot \vartheta_{a}+b_{i}-\sqrt{\Delta}\right)$

The following equations were used to determine the change in speed in deceleration mode:

a) During engine braking:

$a_{i}=K_{\mathrm{B}} \cdot F+K_{f}$

$b_{i}=b_{Z} \cdot U_{T i}^{2} /\left(r_{k}^{2} \cdot \eta_{\mathrm{T}}\right)$

$c_{i}=a_{z} \cdot U_{T i}^{2} /\left(r_{k} \cdot \eta_{\mathrm{T}}\right)+\left(f_{0}+i\right) \cdot m_{a} \cdot 9,8$

where $a_{z}$ and $b_{z}$ are the coefficients depending on the type and design features of the engine.

b) When braking by the engine and brake mechanisms:

$a_{i}=K_{\mathrm{B}} \cdot F+K_{f}$

$b_{i}=b_{z} \cdot U_{T i}^{2} /\left(r_{k}^{2} \cdot \eta_{\mathrm{T}} \cdot m_{a} \cdot 9,8\right)$

$c_{i}=a_{z} \cdot U_{T i}^{2} /\left(r_{k} \cdot \eta_{\mathrm{T}}\right)+\left(f_{0}+i\right) \cdot 9,8+m_{a} \cdot 9,8 \cdot \varphi$ 
where $\varphi$ is the adhesion coefficient.

Traveling fuel consumption at each section and along the entire route as a whole is calculated based on the speed obtained at the previous stage. When the engine power is fully turned on in a section $S_{i}$ long and when the speed changes from $u_{n}$ to $u_{k}$, the fuel consumption is determined by the following equation:

$$
\begin{aligned}
Q_{i}= & a_{Q c} m_{a} \delta_{c p}\left(\frac{v_{k} \cdot v_{H}}{a_{i}} \cdot \frac{b_{i}}{2 a_{i}^{2}} \cdot \ln \left|\frac{a_{i} v_{k}^{2}+b_{i} v_{k}+c_{i}}{a_{i} v_{u}^{2}+b_{i} v_{u}+c_{i}}\right|\right)+ \\
& +\tau_{i}\left(c_{Q c}+a_{Q c} \frac{b_{i}^{2}-2 a_{i} c_{i}}{2 a_{i}}\right)+b_{Q c} S_{i}
\end{aligned}
$$

where $T_{i}$ is the time required for passing the ith section $S_{i}$ long;

$\mathrm{a}_{\mathrm{Qc}}, \mathrm{b}_{\mathrm{Qc}}, \mathrm{c}_{\mathrm{Qc}}$ is the fuel-flow rate equation coefficient

$a_{Q c}=\frac{a_{Q} U_{T i}^{2}}{3600 r_{K}^{2}} ; \quad b_{Q c}=\frac{b_{Q} U_{T i}}{3600 r_{K}} ; \quad c_{Q c}=\frac{c_{Q}}{3600}$

Coefficients $a_{Q}, b_{Q}, c_{Q}$ are calculated depending on the hourly fuel consumption approximated by a polynomial of the second degree:

$Q_{0}=a_{Q} w_{e}^{2}+b_{Q} w_{e}+c_{Q}$

Modeling of the motion process is done according to a rather complex algorithm. The simulation program consists of a main program and four subprograms, which are provided by Kulmukhamedov [3].

\section{RESULTS AND DISCUSSION}

The results of computational studies on the influence of external temperature on the generalized TSP and FE indicators are illustrated by the example of the KamAZ-54112+OdAZ-9385 road train and are presented in Figure 1. The graph is built for three values of the coefficient of utilization of carrying capacity $(\gamma=0 ; \gamma=0.5$; $Y=1)$.

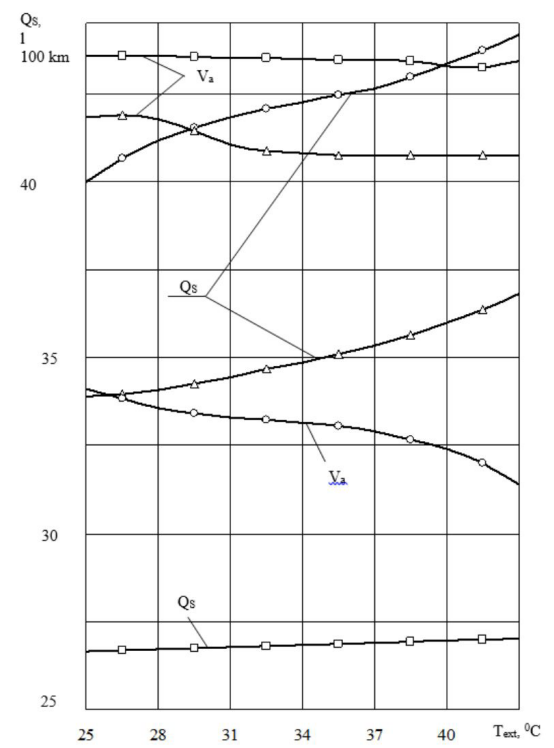

Figure 1: Dependence of fuel consumption and average speed of the road train on external temperature at: $K u=0.6 ; \gamma=1(-0-): y=0.5(-\Delta-) ; y=0(-\square-)$
Figure 1 indicates that with increasing external temperature, fuel consumption increases, and the average speed decreases. The modes of movement of the road train are analyzed to identify the causes of this influence. The analysis of the driving modes (Figures 2,3 ) showed that when the external temperature rises from $+25^{\circ} \mathrm{C}$ to $+43^{\circ} \mathrm{C}$, the distance traveled at the highest gear is reduced. The reason for using lower gears is a change in engine operating conditions and, consequently, a further increase in fuel consumption.

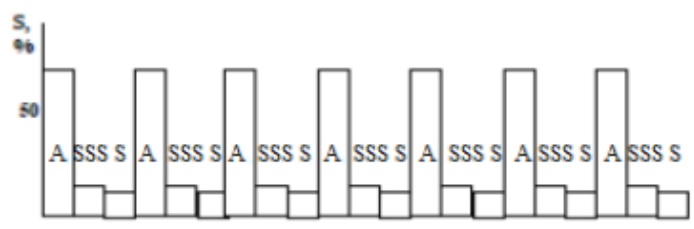

a) $r=1$

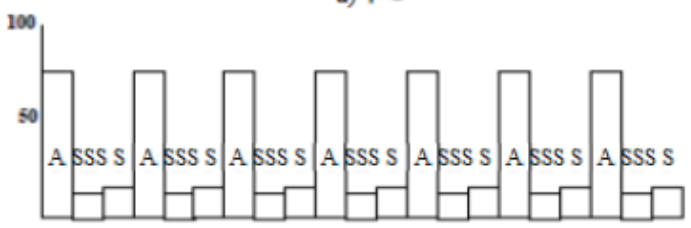

b) $y=0,5$

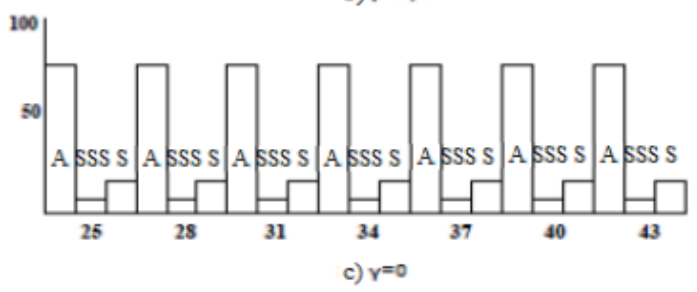

Figure 2: A histogram of the distribution of the KamAZ54112-OdAZ-9385 road train in the modes: $A$ - acceleration; SSS - steady-state speed; $S$ - slowdown

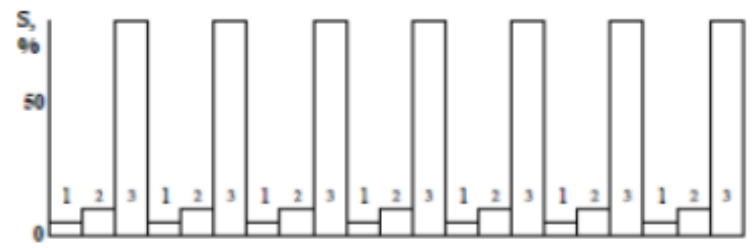

a) $y=1$

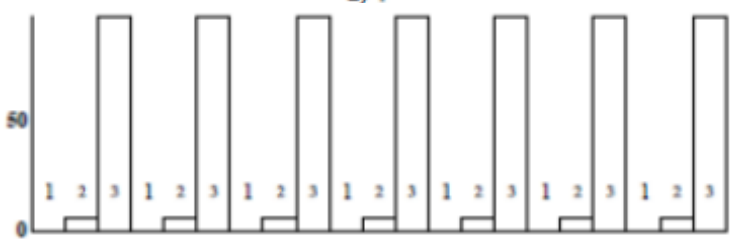

b) $r=0,5$

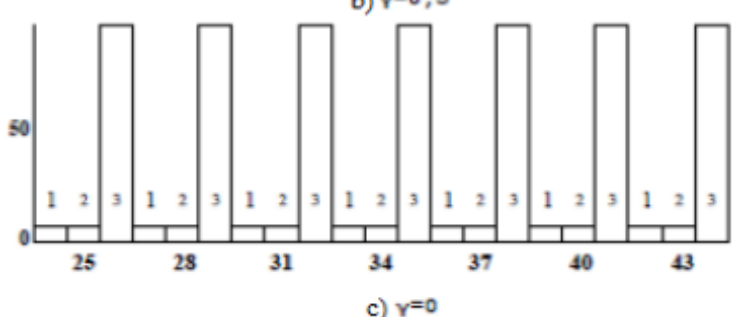

Figure 3: The histogram of the distribution of the path of the KamAZ-54112-OdAZ-9385 road train at the III (1), $I V(2)$, and $V(3)$ gears 
The analysis of the engine operating modes in Figures 4-6 allows for stating that in three weight states $(\gamma=0 ; \gamma=0.5$; $Y=1)$, an increase in the external temperature significantly reduces the engine torque.

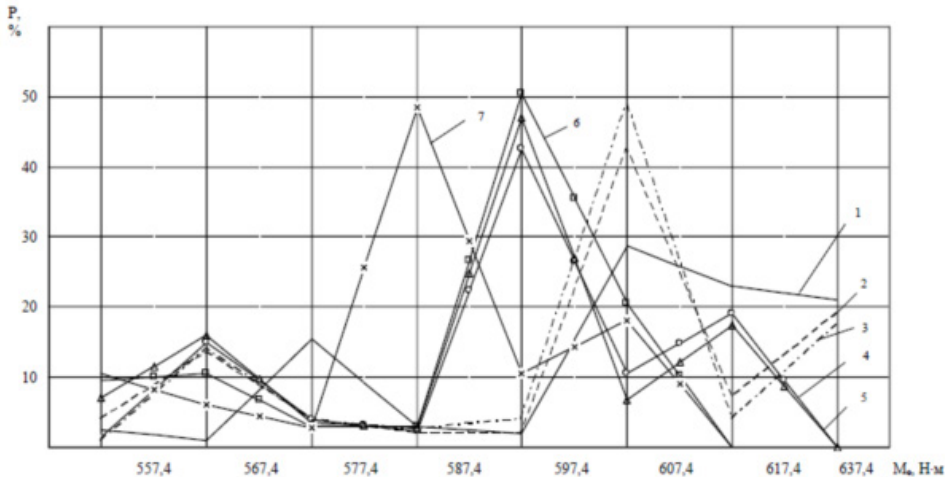

(a)

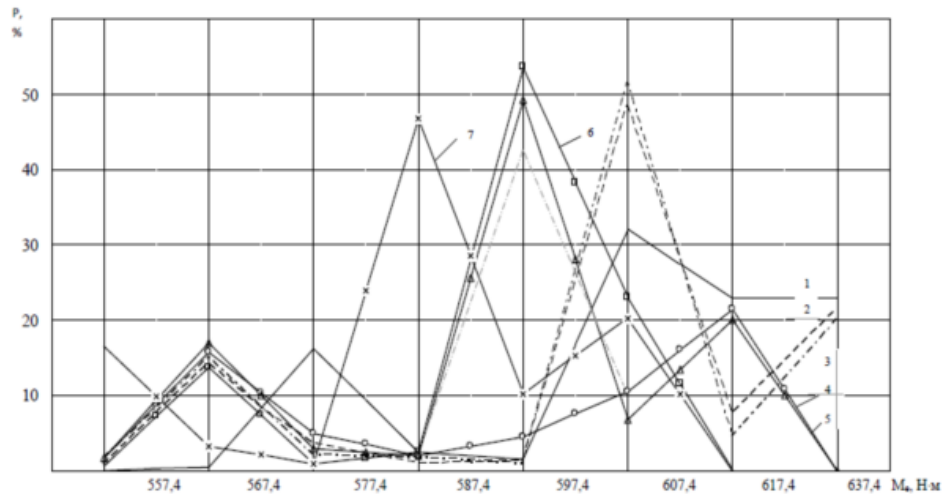

(b)

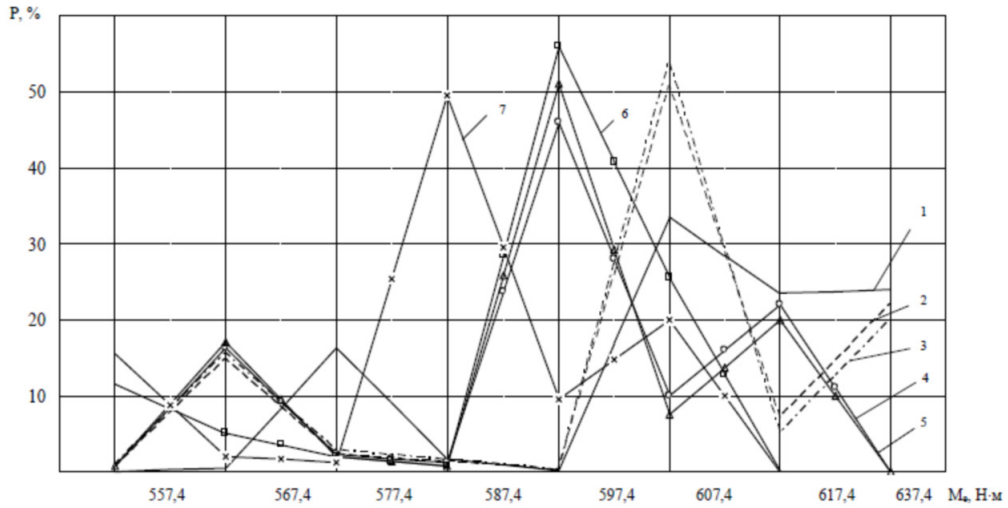

(c)

Figure 4: Distribution curves of engine operating modes during the movement of a road train on the $T$ ashkent-Jizzakh route (torque): a) $y=1$; b) $y=0,5$; c) $y=0$. Respectively, $1-25^{\circ} \mathrm{C} ; 2-28^{\circ} \mathrm{C} ; 3-31^{\circ} \mathrm{C} ; 4-34^{\circ} \mathrm{C}$; $5-37^{\circ} \mathrm{C} ; 6-40^{\circ} \mathrm{C} ; 7-43^{\circ} \mathrm{C}$

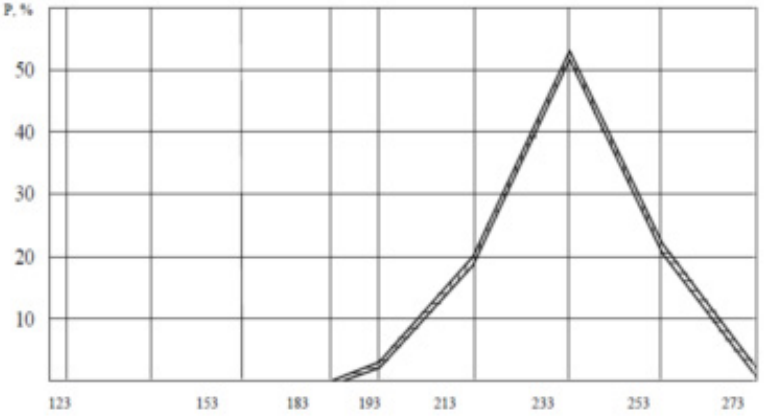

(a)

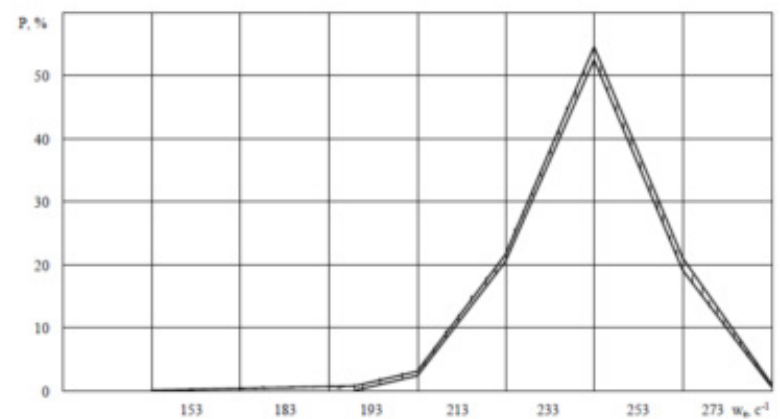




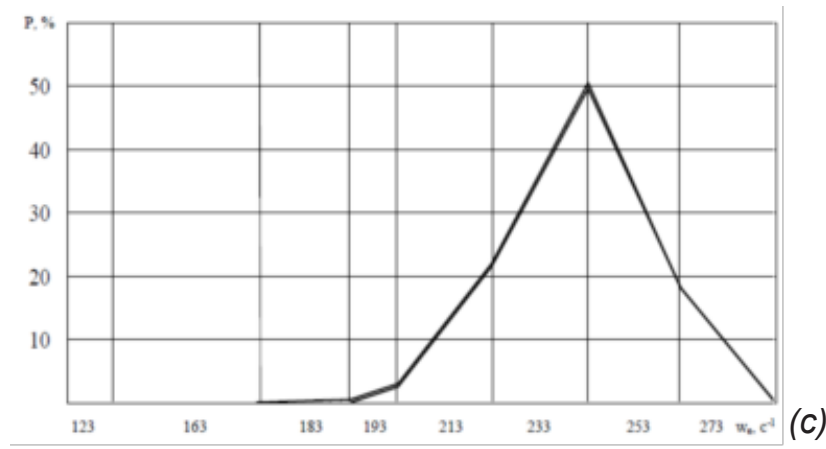

Figure 5: Distribution curves of engine operating modes during the movement of a road train on the

Tashkent-Jizzakh route (crankshaft rotational speed):

a) $y=1$; b) $y=0,5$; c) $y=0$. Text $=25^{\circ} \mathrm{C} \ldots . .43^{\circ} \mathrm{C}$

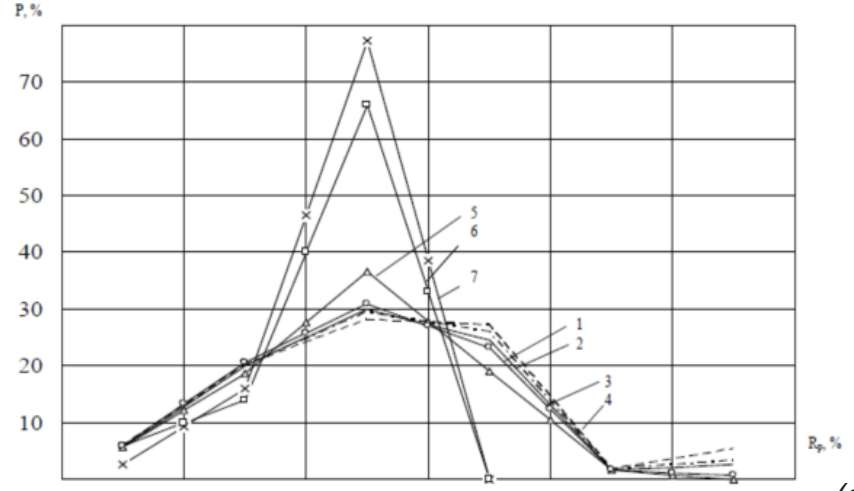

$50 \quad 60$

70

80

100 (a)
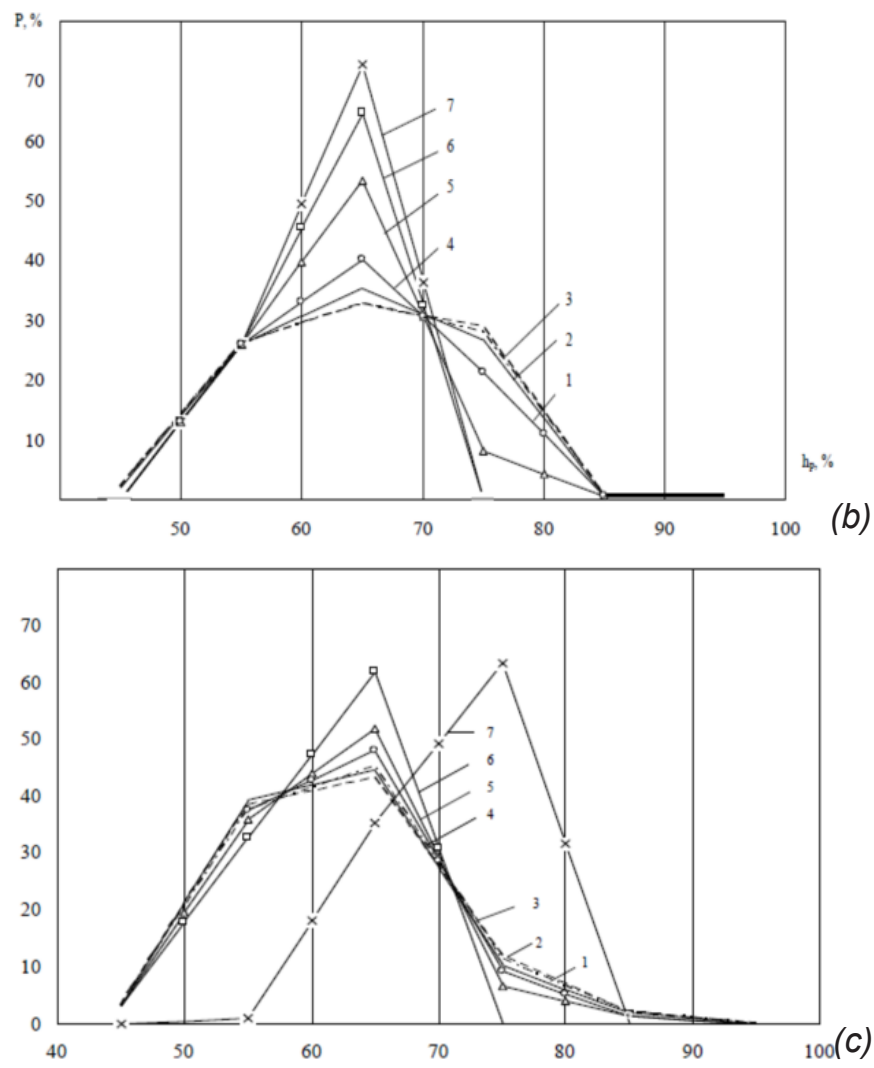

Figure 6: Distribution curves of engine operating modes during the movement of a road train on the

Tashkent-Jizzakh route (rack travel position): a) $y=1$; b) $y=0.5$; c) $y=0.1 \ldots 7$ is the same as in Figure 4
The distribution curves of the torque show that an increase in the external temperature leads to a change like this distribution, and for different weight conditions, the road train has the same character. As the external temperature rises, the distribution values shift toward lower torque values.

Within the range of changes in the external temperature $\mathrm{T}_{\text {ext }}{ }^{-}+25^{\circ} \mathrm{C} \ldots+35^{\circ} \mathrm{C}$, the torque values were in the range from 593.4 to $607.4 \mathrm{~N}_{\mathrm{m}}$, and at $\mathrm{T}_{\text {ext }}+{ }^{-}+35^{\circ} \mathrm{C} \ldots+40^{\circ} \mathrm{C}$ - in the range from 580.4 to $597.4 \mathrm{~N}_{\mathrm{m}}$ and at $\mathrm{T}_{\text {ext }}{ }^{-}+40^{\circ} \mathrm{C} \ldots+43^{\circ} \mathrm{C}$ - in the range from 577.4 to $587.4 \mathrm{~N}_{\mathrm{m}}$.

Reducing engine torque results in the fact that overcoming the resistance to movement at the same gear stage at various external temperatures becomes impossible, and the lower gears are switched on, and the position of the fuel supply control changes towards the maximum values. Thus, the change in fuel consumption with increasing external temperature is a consequence of the complex interaction of the engine and the transmission of the road train.

An analysis of Figure 1 shows that the effect of $T_{\text {ext }}$ on Qs, $U_{\text {rtav }}$ grows with an increase in the total mass of the road train. At the rated carrying capacity $(\gamma=1)$ of the road train, increasing Text from $+25^{\circ} \mathrm{C}$ до $+43^{\circ} \mathrm{C}$ leads to an increase in fuel consumption by $9 \%$. For road trains with $\gamma=0.5$ and $y=0$, these data are 7 and $3 \%$, respectively.

As can be seen from Figure 1, the values of velocity at $y=0.5$ and $y=0$ are significantly higher than at $y=1$. This is because the speed of the road train in the first two cases is limited by road signs and permissible speed values, and for a road train with a full load, the speed is limited by its traction-speed properties and road conditions. At the same time, the road train does not always reach the speed permitted by the traffic rules.

Simulation of the movement modes of the road train and determining the fuel consumption on a real route requires checking the adequacy of the calculation methods. In this case, such a check can be carried out by comparing the calculated data with the test results to establish the modes of motion and fuel consumption of the road train [3].

The results of the calculation and experiment to determine the movement mode and fuel consumption of the road train on the Tashkent-Jizzakh route with a length of $100 \mathrm{~km}$ are shown in Figures 7 and 8.

As can be seen from Figures 7 and 8 , the assessment of the adequacy of the model by the average fuel consumption and the average value of speed is wrongful, because, with equal average performance, the actual situation of the process may differ. The study and analysis of methods comparing experimental and calculated data showed that the most acceptable is the use of the agreement criterion $\mathrm{xu}$ - square. In this case, the probability density of the calculated and experimental data is compared with a certain hypothetical density.

The general methodology for applying the criterion is as follows: the authors take a sample of $\mathrm{N}$ observations 


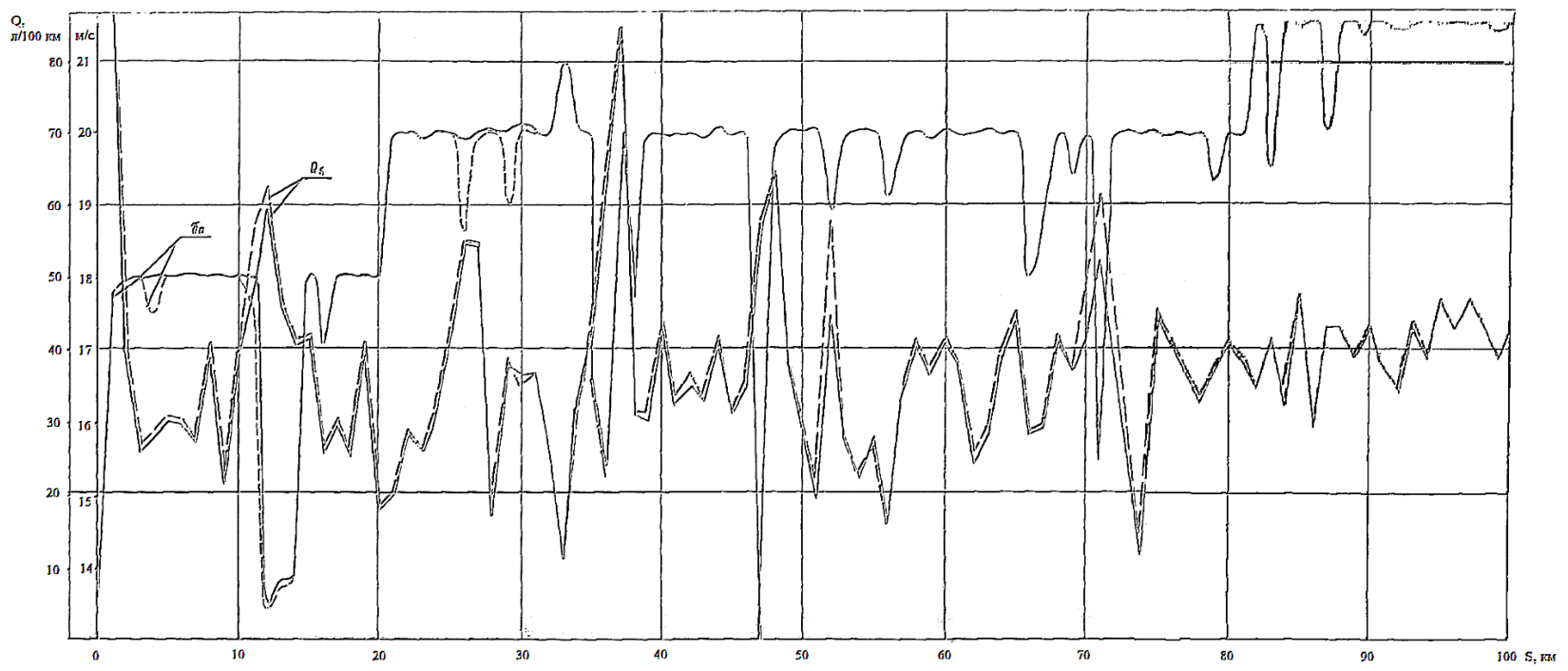

Figure 7: Speed mode and fuel consumption of the KamAZ-54112-OdAZ-9385 road train when simulating traffic on a PC (Tashkent-Jizzakh route) $\gamma=1 ; K_{a r}=0.6 ; T_{\text {ext }}=25^{\circ} \mathrm{C} ;-\cdots--T_{\text {ext }}=43^{\circ} \mathrm{C}$

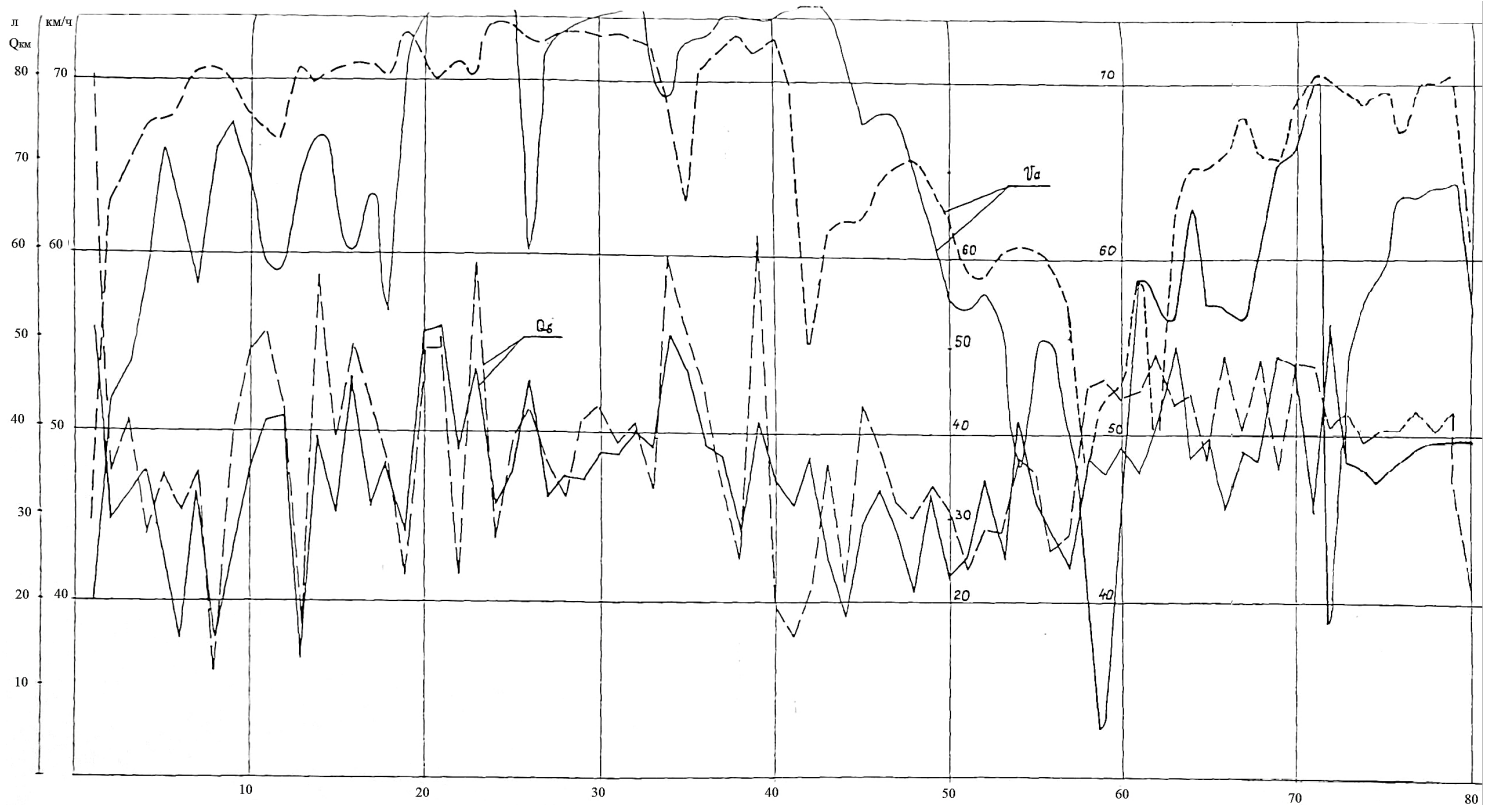

Figure 8: Speed mode and fuel consumption of the KamAZ-54112-OdAZ-9385 road train during experimental studies (Tashkent-Jizzakh route): $y=1 ; K_{a r}=0.6 ; T_{\text {ext }}=25^{\circ} \mathrm{C}$; - - - - - $T_{\text {ext }}=43^{\circ} \mathrm{C}$

of a random variable $X$ with density $P(X)$. The authors group of $\mathrm{N}$ observations at $\mathrm{i}$ intervals, and the authors call grouping intervals, which together form a histogram of frequencies. The number of observations falling into the ith interval is called the observed frequency of the ith interval; denote this frequency $f_{i}$. The number of observations that could fall in the ith interval if the true density of $X$ was $P(X)$ is called the expected frequency of the ith interval; the authors denote it by $\mathrm{F}_{\mathrm{i}}$. The discrepancy between the observed and expected frequencies in each interval is $f_{i}-F_{i}$. To measure the total discrepancy over all intervals, the squares of the discrepancy are normalized with the corresponding expected frequencies, the sum of which gives the sample statistics. $x^{2}=\sum_{i+1}^{n} \frac{\left(f_{i}-F_{i}\right)^{2}}{F_{i}}$

When assessing the adequacy of the model for fuel consumption, a set of fuel consumption values is used as a sample of a random variable.

The authors give an example of checking the adequacy of the model for fuel consumption values obtained by calculation and experimentally at a temperature of $+300 \mathrm{C}$ on the Tashkent-Jizzakh route assuming that these values are distributed according to the normal law.

All calculations necessary for the formation of the criterion are summarized in Table 1. The grouping interval boundaries set by the standard normal distribution are placed in the column under the symbol of $Z_{\alpha}$. The dura- 
Table 1: Calculations performed when constructing the fitting criterion

\begin{tabular}{|c|c|l|l|l|l|l|l|}
\hline $\begin{array}{c}\text { The } \\
\text { number of the } \\
\text { interval }\end{array}$ & $\mathrm{Z}_{\alpha}$ & $x=S \bar{Z}_{\alpha}+\bar{x}$ & $\mathrm{P}$ & $\mathrm{F}=\mathrm{NP}$ & $\mathrm{f}$ & {$[\bar{F}-f]$} & $\frac{(F-f)^{2}}{F}$ \\
\hline 1 & -2.0 & 9.89 & 0.0228 & 16.188 & 20 & 3.812 & 0.896 \\
\hline 2 & -1.6 & 15.93 & 0.0320 & 27.72 & 21 & 1.72 & 0.076 \\
\hline 3 & -1.2 & 21.98 & 0.0603 & 42.813 & 38 & 4.813 & 0.541 \\
\hline 4 & -0.8 & 28.02 & 0.0968 & 68.728 & 61 & 7.728 & 0.869 \\
\hline 5 & -0.4 & 34.05 & 0.1327 & 34.217 & 92 & 2.217 & 0.052 \\
\hline 6 & 0 & 40.094 & 0.1554 & 110.33 & 109 & 1.33 & 0.016 \\
\hline 7 & 0.4 & 46.13 & 0.1554 & 110.33 & 108 & 2.33 & 0.049 \\
\hline 8 & 0.8 & 52.17 & 0.1327 & 94.217 & 89 & 5.217 & 0.288 \\
\hline 9 & 1.2 & 58.21 & 0.0968 & 68.728 & 76 & 7.272 & 0.769 \\
\hline 10 & 1.6 & 64.25 & 0.0603 & 42.813 & 49 & 6.187 & 0.145 \\
\hline 11 & 2.0 & 70.29 & 0.0320 & 22.72 & 26 & 3.28 & 0.144 \\
\hline 12 & & & 0.0228 & 16.188 & 21 & 4.812 & 0.297 \\
\hline
\end{tabular}

tion of the intervals $\Delta \mathrm{X}=0.4 \mathrm{~S}$. The next column contains the same values in another unit of measurement in $1 / 100$ $\mathrm{km}$. Then, using the value of $Z_{\alpha}$ according to the data of standard tables, the authors determine the probability $\mathrm{P}$ of the indicators of sample values in each of the grouping intervals. Multiplying $\mathrm{P}$ by sample size $\mathrm{N}$ gives the expected frequencies for each interval.

These frequencies are shown in the column marked with $\mathrm{F}$. The authors calculate the observed frequencies (f) using the interval boundaries. After that, calculating and summing up the normalized squares of the discrepancies of the expected and observed frequencies, the authors obtain $\mathrm{x}^{2}$.

According to the experimental data obtained when testing the road train on the Tashkent-Jizzakh route $\left(T_{\text {ext }}=30^{\circ} \mathrm{C}\right)$, the calculated value of $x^{2}$ is 4.144 . The amount of degree of freedom equals to $n=K-3=9$.

The distribution of the hypothesis of normality of distribution is found in standard tables, and then the authors obtain $x_{9: 000.05}^{2}=16,92$, i.e., $x^{2}<x^{2}$. Consequently, the hypothesis of normality is accepted with a significance level of $\alpha=0.05$. In the same way, the value for the calculated data is determined, which is equal to $-\mathrm{x}^{2}=5.92$.

It follows that the experimental data are distributed according to the normal law, i.e., does not differ from the standard normal distribution with a significance level of $\alpha=0.05$. This allows for assuming that the model is adequate with the experimental data for the selected significance level.

\section{CONCLUSIONS}

Based on the graph shown in Figure 1, the authors conclude that the influence of external temperature on fuel consumption and average speed with an increase in the total mass of the cargo-carrying vehicle. At the
$N=710 ; \bar{N}=40,094 ; S=15.098 ; n=9 ; x^{2}=4.144$

rated carrying capacity of the road train, an increase in the external temperature from $+25^{\circ} \mathrm{C}$ to $+43^{\circ} \mathrm{C}$ leads to an increase in fuel consumption by $9 \%$. For road trains with load factors of 0.5 and 0 , these data are 7 and $3 \%$, respectively. Thus, with an increase in the external temperature, there are an increase in fuel consumption and a decrease in the speed of movement in all weighted states of motor vehicles.

The manuscript made it clear that as the external temperature rises, there are an increase in fuel consumption and a decrease in the speed of movement in all weighted states of vehicles.

The influence of the external temperature decreases, with a smaller mass of the road train, which indicates the special importance of research to find ways to reduce the resistance to movement of road trains operating in a hot, dry climate.

The mathematical modeling of the process of moving a truck on a real route showed that the modified mathematical model, which considers the effects of elevated external temperatures, allows for determining objectively the degree of efficiency of a cargo-carrying vehicle by traction and speed properties and fuel economy to these conditions, as well as at the design stage.

\section{REFERENCES}

1. Chen, W., Bu, Q., Liu, Z., Li, Q., Sun, B., \& Li, M. (2016). Power system design for a fuel cell hybrid power tram. Journal of Southwest Jiaotong University, 51(3). http://jsju.org/index.php/journal/article/ view/119 
2. Peng, Q., Li, J., Yang, Y., \& Wen, C. (2016). Influences of high-speed railway construction on railway transportation of China. Journal of Southwest Jiaotong University, 51(3). http://jsju.org/index.php/ journal/article/view/114

3. Kulmukhamedov, D. R. (2018). The scientific basis for improving the efficiency of vehicles in hot and dry climates. Tafakkur Kanoti, Tashkent.

4. Zezyulin, D., Makarov, V., Belyaev, A., Ogorodnov, S., \& Belyakov, V. (2014). Modeling of roads impacts for life prediction of light commercial vehicles parts. FISITA 2014 World Automotive Congress. http:// www.fisita2014.com/test/programme/sessions/ F2014-LWS-040

5. Zezyulin, D., Makarov, V., Belyaev, A., Ogorodnov, S., \& Belyakov, V. (2014). Methodology of roadway impacts modeling to predict the fatigue life of vehicles. Acta Technica Jaurinensis, 7(3), 267-279. doi: 10.14513/actatechjaur.v7.n3.277

6. Zagarin, D. A., \& Kulmukhamedov, D. R. (2019). Determination of the effect of external temperature on the engine speed characteristic. Collection of Materials of the International Scientific and Technical Seminar "Global Partnership as a Condition and Guarantee of Sustainable Development". TIPSEAD, Tashkent.

7. Gusakov, S. V., Afanasyeva, I. V., Mokhsen, A., \& Markov, V. A. (2015). Fuel efficiency of a power plant of a motor vehicle with an electromechanical transmission. Bulletin of Volgograd State University. Series 10, Innovation Activities, 1.
8. Karnaukhova, I. V. (2018). Fuel economy during truck operation due to adjustment of air parameters at the engine inlet. PhD thesis. Tyumen.

9. Karnaukhov, V. N., \& Karnaukhov, O. V. (2016). Determination of effective specific fuel consumption for various types of engines taking into account density, pressure and air temperature. Bulletin of Kurgan State Agricultural Academy, 4.

10. Belov, A. G., \& Anisimov, I. A. (2006). The effect of low external temperatures on vehicle performance. Bulletin of International Academy of Ecology and Life Protection Sciences, 11(6), 5-9.

11. Gusakov, S. V., Markov, V. A., \& Mikhryachev, D. V. (2012). Calculation and experimental methodology for adjusting the driving cycle for the phase of vehicle movement in urban conditions. Bulletin of Higher Educational Institutions, 5.

12. Ogorodnov, S. M., Tikhomirov, A. N., \& Maleev, S. I. (2015). Assessment of the possibility of using analytical methods in studying the fuel economy of cars. Bulletin of Higher Educational Institutions. Mechanical Engineering, 2, 53-62. 